\title{
Longitudinal, virological, and serological assessment of hospitalized COVID-19 patients
}

\author{
Lucia Signorini ${ }^{1} \cdot$ Maria Dolci $^{1}$ - Nicolò Castelnuovo ${ }^{2} \cdot$ Luigia Crespi $^{2} \cdot$ Barbara Incorvaia $^{2} \cdot$ Pietro Bagnoli $^{2}$. \\ Silvia Parapini ${ }^{3}$. Nicoletta Basilico ${ }^{1}$. Cristina Galli ${ }^{3}$. Federico Ambrogi ${ }^{4,5}$. Elena Pariani ${ }^{3}$. Sandro Binda ${ }^{3}$. \\ Rosalia Ticozzi ${ }^{1} \cdot$ Pasquale Ferrante $^{1,2}(\mathbb{0}) \cdot$ Serena Delbue ${ }^{1}$
}

Received: 2 September 2021 / Revised: 14 October 2021 / Accepted: 9 November 2021 / Published online: 7 January 2022

(c) Journal of NeuroVirology, Inc. 2022

\begin{abstract}
Here we described the virological and serological assessment of 23 COVID-19 patients hospitalized and followed up in Milan, Italy, during the first wave of COVID-19 pandemic. Nasopharyngeal (NPS), anal swabs, and blood samples were collected from 23 COVID-19 patients, at hospital admission, and periodically up to discharge, for a median time of 20 days (3-83 days). RNA was isolated and tested for SARS-CoV-2 by qRT-PCR; anti-SARS-CoV-2 IgM and IgG antibody titers were evaluated in serum samples by ELISA. SARS-CoV-2 genome was detected in the NPS swabs of the 23 patients, at the admission, and 8/19 (42.1\%) were still positive at the discharge. Anal swabs were positive to SARS-CoV-2 RNA detection in 20/23 (86.9\%) patients; 6/19 (31.6\%) were still positive at discharge. The mean time of RNA negative conversion was 17 days (4-36 days) and 33 days (4-77 days), for NPS and anal swabs, respectively. SARS-CoV-2-RNA was detected in the blood of 6/23 (26.1\%) patients. Thirteen/23 (56.5\%) and 17/23 (73.9\%) patients were seropositive for IgM and IgG, respectively, at the admission, and the median IgM and IgG levels significantly $(p<0.05)$ increased after 13 days. Although the limited cohort size, our report provides evidence that SARS-CoV-2 is shed through multiple routes, with important implications in healthcare settings.
\end{abstract}

Keywords SARS-CoV-2 $\cdot$ Nasopharyngeal swabs $\cdot$ Anal swabs $\cdot$ Blood $\cdot$ Anti-SARS-CoV-2 antibodies

\section{Background}

Coronavirus disease 2019 (COVID-19) is a rapidly escalating world pandemic due to Severe Acute Respiratory Sindrome-CoronaVirus-2 (SARS-CoV-2) infection. SARSCoV-2 was isolated for the first time at the beginning of 2020, at Wuhan Hospital, in China (Zhu et al. 2020). Italy, in particular Lombardy region, was one of the pandemic epicenters during the first wave (Villani et al. 2020).

The SARS-CoV-2 genome shows high sequence similarity with other coronaviruses, the Betacoronaviruses SARS$\mathrm{CoV}$, and Middle East Respiratory Syndrome-CoronaVirus (MERS-CoV) (Koyama et al. 2020). The positive singlestrand RNA (ssRNA) is about $30 \mathrm{kbp}$, and the genome contains the open reading frames (ORFs), coding for the spike (S gene), envelope (E gene), membrane (M gene), and nucleocapsid ( $\mathrm{N}$ gene) proteins, the ORF1ab polyproteins,

Pasquale Ferrante

Pasquale.ferrante@unimi.it

Extended author information available on the last page of the article and several accessory proteins, known as ORF3a, ORF3b, ORF6, ORF7a, ORF7b, ORF8, ORF9b, ORF9c, and ORF10 (Alanagreh et al. 2020).

As for the other human coronaviruses, SARS-CoV-2 is transmitted through respiratory droplets, as well as direct contact (Meselson 2020). However, emerging evidences showed that SARS-CoV-2 causes a systemic infection, due to the presence of the ACE-2 receptors in different body districts (Hikmet et al. 2020).

The gut involvement by SARS-CoV-2 (Jin et al, 2021), and its presence in the feces and in wastewater (Ahmad et al. 2021; Zhang et al. 2021), raises hypothesis about the role of fecal shedding in viral transmission. Additionally, several studies have sought SARS-CoV-2 RNA in blood, with variable results (Ahmed Moustafa 2020; Andersson et al. 2020; Lin et al. 2021; Novazzi et al. 2020; Peng et al. 2020; Sun et al. 2020; Wang et al. 2020; Zhang et al. 2020a, b; Loubaki et al. 2021).

Immune response to SARS-CoV-2 is characterized by humoral immunity, with the presence of both IgM and IgG antibodies, which are produced 6 to 15 days after the 
COVID-19 onset (Liu et al. 2020b): particularly, antibodies were detected in $<40 \%$ of COVID-19 patients after 1 week from the manifestation of symptomatology, and in the totality of the patients after 15 days (Zhao et al. 2020; Masiá et al. 2021).

The main purpose of this study was to describe the virological and serological assessment of 23 COVID-19 patients hospitalized in Milan, Italy, during the first epidemic wave and followed up to 83 days after the diagnosis.

\section{Material and methods}

\section{Study design}

This single-center prospective observational study was conducted on 23 patients hospitalized at the Istituto Clinico Città Studi (ICCS) hospital in Milan (Lombardy, Italy), in April and May 2020. Sex, age, diagnosis at the Emergency Room (ER) admission, report of gastrointestinal symptoms during the follow-up, and discharge type are summarized in Table 1. Nasopharyngeal swabs (NPS) were collected from each patient at the admission time (T0), whenever possible every $72 \mathrm{~h}$, and at the discharge, for subsequent molecular
SARS-CoV-2 tests. Diagnostic assessment of SARS-CoV-2 in NPS was conducted at the Department of Biomedical Science for Health, University of Milan, and the positive NPS confirmed the COVID-19 diagnosis in the 23 enrolled patients. Additionally, anal swabs and peripheral blood samples were collected at the admission (T0) and every $72 \mathrm{~h}$. Serum samples were collected at the admission and, where possible, after 13 days. Clinical specimens were collected upon approval of the Local Ethical Committee and signature of the informed consent (Fondazione Ca' Granda, Ospedale Maggiore, Milano, Italy approved the protocol 456_2020, on May 2020).

\section{RNA isolation from clinical specimens}

RNA was extracted from NPS, with the commercial method (QIAamp Viral RNA Mini kit, QIAGEN) following the manufacturer's instructions, while it was isolated starting from $150 \mu \mathrm{L}$ anal swab medium, using the NucleoSpin RNA virus kit (Macherey-Nagel, Germany), according to the manufacturer's instructions.

Blood samples, previously stored in $700 \mu \mathrm{L}$ QIAzol reagent (Qiagen, Germany), were thawed, mixed, and incubated for $5 \mathrm{~min}$ at room temperature. Then, $140 \mu \mathrm{L}$ of
Table 1 Patients' demographic and clinical data

\begin{tabular}{|c|c|c|c|c|c|}
\hline Patient & Gender & Age (Years) & $\begin{array}{l}\text { Clinical diagnosis at the } \\
\text { admission }\end{array}$ & $\begin{array}{l}\text { Gastrointestinal } \\
\text { symptoms }\end{array}$ & Discharge \\
\hline \#1 & $\mathrm{F}$ & 43 & SARS-CoV-2 pneumonia & no & Transferred \\
\hline \#2 & M & 79 & SARS-CoV-2 pneumonia & no & Ordinary \\
\hline \#3 & M & 54 & SARS-CoV-2 pneumonia & no & Transferred \\
\hline \#4 & M & 82 & n.a & no & Deceased \\
\hline \#5 & $\mathrm{F}$ & 53 & SARS-CoV-2 pneumonia & no & Transferred \\
\hline \#6 & M & 81 & SARS-CoV-2 pneumonia & no & Deceased \\
\hline \#7 & M & 80 & Respiratory failure & yes & Transferred \\
\hline$\# 8$ & M & 62 & Respiratory failure & no & Transferred \\
\hline \#9 & M & 63 & Undefined pneumonia & no & Ordinary \\
\hline \#10 & $\mathrm{F}$ & 81 & Respiratory failure & no & Ordinary \\
\hline \#11 & $\mathrm{F}$ & 84 & Respiratory failure & yes & Transferred \\
\hline$\# 12$ & $\mathrm{~F}$ & 86 & SARS-CoV-2 pneumonia & no & Transferred \\
\hline \#13 & M & 48 & Respiratory failure & no & Ordinary \\
\hline \#14 & $\mathrm{F}$ & 87 & Respiratory failure & yes & Transferred \\
\hline$\# 15$ & $\mathrm{~F}$ & 87 & SARS-CoV-2 pneumonia & yes & Transferred \\
\hline \#16 & M & 42 & SARS-CoV-2 pneumonia & no & Transferred \\
\hline \#17 & $\mathrm{F}$ & 52 & SARS-CoV-2 pneumonia & no & Transferred \\
\hline \#18 & M & 69 & Respiratory failure & no & Ordinary \\
\hline \#19 & M & 40 & Respiratory failure & no & Transferred \\
\hline \#20 & $\mathrm{F}$ & 89 & Respiratory failure & yes & Deceased \\
\hline \#21 & M & 77 & SARS-CoV-2 pneumonia & no & Transferred \\
\hline \#22 & $\mathrm{F}$ & 44 & SARS-CoV-2 pneumonia & yes & Ordinary \\
\hline$\# 23$ & $\mathrm{~F}$ & 66 & SARS-CoV-2 pneumonia & yes & Deceased \\
\hline
\end{tabular}

n.a. information not available 
Table 2 Primer sequences for SARS- CoV-2 N1 gene realtime PCR

\begin{tabular}{lll}
\hline Primers & Position* & Sequences $\left(\mathbf{5}^{\prime} \mathbf{-} \mathbf{3}^{\prime} \mathbf{)}\right.$ \\
\hline 2019-nCoV_N1-F & $28,287-28,306$ & GAC CCC AAA ATC AGC GAA AT \\
2019-nCoV_N1-R & $28,335-28,358$ & TCT GGT TAC TGC CAG TTG AAT CTG \\
2019-nCoV_N1-P & $28,309-28,332$ & FAM-ACC CCG CAT TAC GTT \\
& & TGG TGG ACC-BHQ1 \\
\hline
\end{tabular}

*Nucleotide positions are referred to SARS-CoV-2 isolate Wuhan-Hu-1 complete genome (NC_045512.2) chloroform were added, the tube was shaken vigorously for $15 \mathrm{~s}$, and incubated for $3 \mathrm{~min}$. The mixture was centrifuged at $12,000 \mathrm{~g}$ for $15 \mathrm{~min}$ at $4{ }^{\circ} \mathrm{C}$. The aqueous upper phase, containing RNA, was transferred into a new tube, and the RNA isolation was performed according to the QIAamp RNA Blood Mini kit manufacturer's protocol (Qiagen, Germany). RNA quality was evaluated using NanoPhotometer NP80 (Implen, Germany).

\section{Real-time PCR for SARS-CoV-2 N1 gene amplification}

SARS-CoV-2 N1 gene presence was assessed by means of AgPath-ID One-Step RT-PCR assay (ThermoFisher, USA), using the 7500 Real Time PCR system instrument (ThermoFisher, USA). The primer and probe sequences have been published by CDC (Table 2). Each sample was tested for SARS-CoV-2 positivity using the CDC 2019-Novel Coronavirus (2019-nCoV) Real-Time RT-PCR Diagnostic Panel for the qualitative detection of nucleic acid from the 2019$\mathrm{nCoV}$ (N1 gene).

The standard curve was constructed by using a serially diluted plasmid pEX-A128-nCoV_all (Eurofins, Luxemburg), containing part of the SARS-CoV-2 genome $\left(3 \times 10^{7}-3 \times 10^{1}\right.$ copies $\left./ \mu \mathrm{L}\right)$. Samples were analyzed in duplicate, and a negative control, consisting of mix supplemented of water, was added. The limit of viral genome detection was evaluated as 3 copies/reaction.

\section{PCR for SARS-CoV-2 RBD and ORF8 genomic regions}

The Receptor Binding Domain (RBD, part of the S gene) and ORF8 sequences were amplified from the positive samples, using the one-Step RT-PCR kit (ThermoFisher, USA). The nucleotide sequence and the position of each set of primers are reported in Table 3. The reaction was performed in a final volume of $50 \mu \mathrm{L}$, composed as follows: $25 \mu \mathrm{L}$ of $2 \times$ Reaction mix, $2 \mu \mathrm{L}$ of SuperScript III RT/Platinum Taq Mix (ThermoFisher, USA), $1 \mu \mathrm{L}$ of Forward primer $(10 \mu \mathrm{M}), 1 \mu \mathrm{L}$ of Reverse primer $(10 \mu \mathrm{M})$, and a variable volume from 1 to $10 \mu \mathrm{L}$ of RNA samples, depending on SARS-CoV-2 load. The PCR steps were as follows: 1 cycle at $50{ }^{\circ} \mathrm{C}$ for $15 \mathrm{~min}$ and at $95{ }^{\circ} \mathrm{C}$ for $2 \mathrm{~min}$, followed by 40 cycle at $95{ }^{\circ} \mathrm{C}$ for $15 \mathrm{~s}$; the annealing temperatures were $54{ }^{\circ} \mathrm{C}$ for RBD and $57{ }^{\circ} \mathrm{C}$ for ORF8 for $30 \mathrm{~s}$, while the polymerization temperature was $68^{\circ} \mathrm{C}$ for $40 \mathrm{~s}$. Finally, the last step was conducted at $68^{\circ} \mathrm{C}$ for $5 \mathrm{~min}$. Right sizes of the RBD and ORF8 amplification products (lengths: $1000 \mathrm{bp}$, and $594 \mathrm{bp}$, respectively) were checked on $1.5 \%$ agarose gels in a $0.5 \times \mathrm{TBE}$ buffer, by electrophoresis. PCR products were purified using the QIAquick Gel Extraction Kit (QIAgen), following the manufacturer's instructions. Automatic sequencing of the fragments was performed by an external facility (Eurofins Genomics, Germany), with the Sanger method. The homology of sequence was searched through the NCBI site (USA) using BLAST, comparing the amplified fragments to the reference Wuhan-Hu-1 strain (NC_045512.2). Multiple sequence alignment (MSA) of all nucleotide sequences were carried out in the EMBL-EBI Clustal Omega server to investigate sequence conservation (Sievers et al. 2011). The phylogenetic tree was constructed in the Interactive Tree of Life (iTOL) online tool (Ciccarelli et al. 2006).

\section{Anti SARS-CoV-2 IgM and IgG detection}

Anti SARS-CoV-2 IgM and IgG antibody titers were evaluated in serum samples using the MAGLUMI ${ }^{\mathrm{TM}}$ 2019-nCoV IgG and IgM kits on a MAGLUMI TM 800 instrument (Snibe, China), following manufacturers' protocol. IgM and IgG serum titers were expressed as AU/mL, with manufacturer's cutoff $>1 \mathrm{AU} / \mathrm{mL}$.
Table 3 RBD and ORF8 primer positions and sequences

\begin{tabular}{lll}
\hline Primer & Position* & Sequences $\left(\mathbf{5}^{\prime} \mathbf{- 3}^{\prime}\right.$ ) \\
\hline SARS Cov-2 RBD Fw & $22,428-22,448$ & AGACTGTGCACTTGACCCTC \\
SARS Cov-2 RBD Rev & $23,428-23,407$ & AACAGGGACTTCTGTGCAGTT \\
SARS Cov-2 ORF8 Fw & $27,716-27,738$ & TGTTTATAACACTTTGCTTCACA \\
SARS Cov-2 ORF8 Rev & $28,309-28,290$ & TGCATTTCGCTGATTTTGGG \\
\hline
\end{tabular}

*Nucleotide positions are referred to SARS-CoV-2 isolate Wuhan-Hu-1 complete genome (NC_045512.2) 


\section{Statistical analysis}

Categorical and numerical variables were described using medians, confidence interval 95\% (CI95), and interquartile range (IQR). Data were compared using Fisher's exact test for SARS-CoV-2 prevalence's and distributions or Mann-Whitney $U$ test for SARS-CoV-2 viral loads as appropriate. Significances were defined as $p$-value $<0.05$. Viral load at follow-up was quantified considering, for patients with multiple measurements, the last available. For anal swabs, multiple measurements were available for 15 patients and the log geometric means were reported at each followup time.

\section{Results}

\section{Study population}

Twenty-three patients were enrolled in the study. Median age of patients was 67 years (range: 43-89); 52.2\% (12/23) were female. Twelve/23 (52.2\%) patients have pneumonia, $9 / 23(39.1 \%)$ patients had respiratory failure, and $1 / 23$ (4.3\%) had undefined pneumonia. Patients were followed up from the admission to the discharge, for a median time of 20 days (range: 3-83 days). A careful evaluation of the possible presence of gastrointestinal disorders and symptoms was conducted by evaluating the daily medical and nursing diary of each patient. The gastrointestinal disorders taken into consideration were alvus disorders (diarrhea and constipation), nausea, loss of appetite, and epigastralgia. Sixteen/23 (69.6\%) patients did not present any gastrointestinal symptoms during the hospitalization time; $4 / 23$ (17.4\%) had constipation and nausea for a few days, while $3 / 23$ (13.0\%) suffered of diarrhea. The discharge was due to transfer to other quarantine structures $(12 / 23,52.2 \%)$, to remission $(7 / 23,30.4 \%)$, or to death $(4 / 23,17.4 \%)$. Among the transferred patients, $6 / 12(50 \%)$ were still SARS-CoV-2 positive at the time of the discharge, and were lost to the follow up (Table 1; and S1).

\section{SARS-CoV-2 prevalence in NPS}

The analytical description of the results obtained analyzing the clinical specimens longitudinally collected from the patients is summarized in Tables S1, S2, and S3 in the supplementary material section.

COVID-19 diagnosis was confirmed in all the enrolled patients by the SARS-CoV-2 positivity of the NPS collected at the hospital admission. Four patients deceased, so the prevalence at the discharge was evaluated on 19 patients. Eleven/19 (57.9\%, CI95 22\%) had a negative NPS at the discharge; the mean time of nucleic acid negative conversion was 33 days (range: 4-77 days). Interestingly, three patients showed alternance of results in NPS during the follow-up.

\section{SARS-CoV-2 prevalence in anal swabs}

SARS-CoV-2 RNA was detected in the anal swabs of 20/23 (86.9\%, CI95 14\%) patients: 7/23 (30.4\%, CI95 $18 \%$ ) patients showed SARS-CoV-2 positivity at T0, 10/23 (43.5\%, CI95 20\%) became SARS-CoV-2 positive during the follow up, and 6/19 (31.6\%, CI95 21\%) were still positive at the discharge. The analytical description of the results in each anal swab is summarized in Tables S1, S2, and $\mathrm{S} 3$ in the supplementary material section. The mean time of nucleic acid negative conversion was 17 days (range: 4-36 days). Of note, 7/23 (30.4\%) patients experienced gastrointestinal symptoms; all but one showed SARS-CoV-2 anal swab positivity, and 2 of them deceased.

\section{SARS-CoV-2 prevalence in blood}

SARS-CoV-2-RNA was present in the blood of 4/23 (17.4\%, CI95 15\%) patients at the admission, while $2 / 23(8.7 \%$, CI95 $12 \%)$ were SARS-CoV-2-RNA during the follow-up, and only one (1/19, 5.3\%, CI95 9.8\%) was still positive at the discharge. Of note, SARS-CoV-2-RNA was found in both anal swab and blood of 6/23 (26.0\%, CI95 17.8\%) patients; 2 of them deceased.

\section{SARS-CoV-2 viral load in biological samples}

At the time of admission, geometric mean of viral loads were $1.58 \times 10^{5}$ copies $/ \mathrm{mL}\left(95 \% \mathrm{CI}: 4.84 \times 10^{4}-5.18 \times 10^{5}\right.$ copies/ $\mathrm{mL}), 2.99 \times 10^{2}$ copies $/ \mathrm{mL}\left(95 \% \mathrm{CI}: 1.37 \times 10^{2}-6.53 \times 10^{2}\right.$ copies/mL), and $1.88 \times 10^{2}$ copies $/ \mathrm{mL}$ (95\%CI: $4.12 \times 10-85.66 \times 10^{2}$ copies $\left./ \mathrm{mL}\right)$ in NPSs, anal swabs and blood samples, respectively.

Viral load analysis during the follow up showed the following geometric mean values: $1.17 \times 10^{4}$ copies $/ \mathrm{mL}$ (95\%CI: $1.7 \times 10^{3}-8.10 \times 10^{4}$ copies $/ \mathrm{mL}$ ), $3.53 \times 10^{2}$ cop$\mathrm{ies} / \mathrm{mL}\left(95 \% \mathrm{CI}: 1.46 \times 10^{2}-8.55 \times 10^{2}\right.$ copies $\left./ \mathrm{mL}\right)$, and $1.50 \times 10^{2}$ copies $/ \mathrm{mL}\left(95 \% \mathrm{CI}: 2.88-7.81 \times 10^{3}\right.$ copies $\left./ \mathrm{mL}\right)$ in NPSs, anal swabs, and blood samples, respectively. The SARS-CoV-2 load in anal swabs at each follow-up time is reported in Fig. 1. Analytical description of viral load of the NPSs and anal swabs collected from each patient during the follow-up is shown in Fig. 1S, and in Table 4S.

\section{SARS-CoV-2 ORF8 and RBD sequence analysis}

In order to confirm the SARS-CoV-2 detection, sequence analysis of the SARS-CoV-2 RBD and ORF8 genomic 
Fig. 1 Description of SARSCoV-2 load in anal swabs collected during the time of hospitalization from each patient. The solid black line shows the log geometric mean calculated on patients with positive tests. The calculation was performed if at least two patients showed positivity. The two dashed black lines are the $95 \%$ confidence interval of the log geometric mean. The red squares represent the percentage of patients testing positive out of the number tested (reported immediately above the $x$ axis)

\section{Anal Swabs}

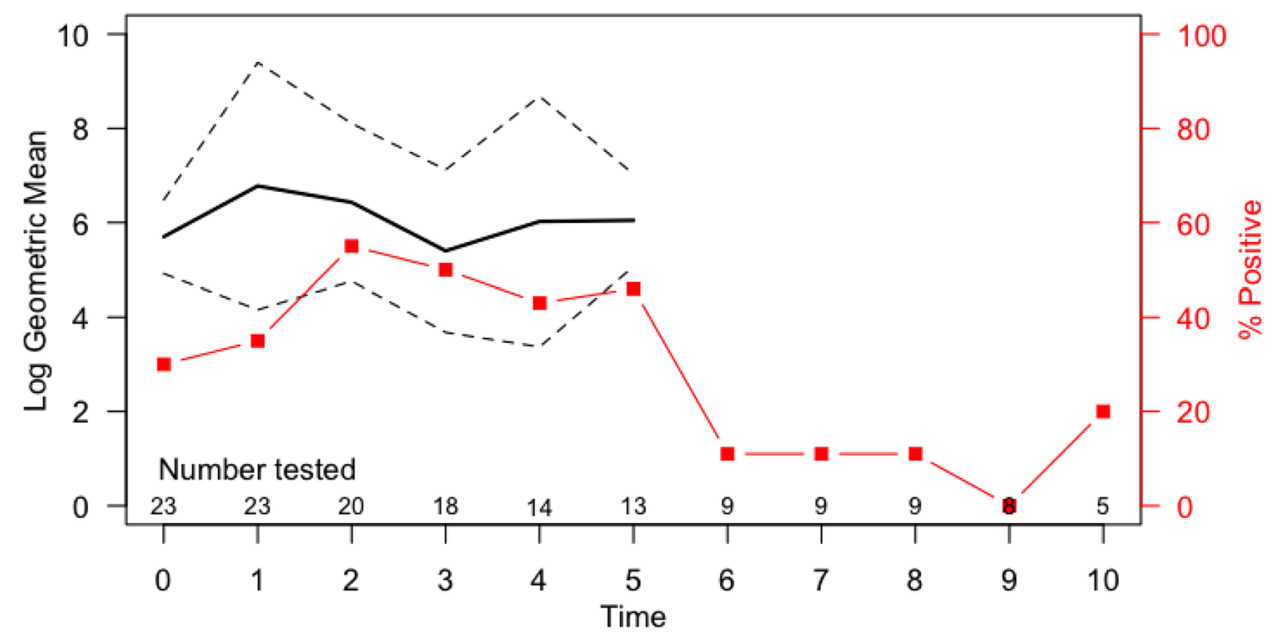

regions was conducted on 7 and 3 RNA, respectively, isolated from anal swabs. The RBD sequences showed high homology with the Wuhan-Hu-1 strain (accession numbers NC_045512.2, YP_009724390.1), and the phylogenetic tree is shown in Fig. 2, while the three analyzed ORF8 sequences showed $100 \%$ homology with Wuhan-Hu-1 strain.

\section{Anti-SARS-CoV-2 IgM and IgG titers}

Anti-SARS-CoV-2 IgM and IgG titers were evaluated at the admission, and where possible (18/23 patients, $78.3 \%)$ after 13 days. A total of 13/23 (56.5\%) and 17/23 (73.9\%) patients were seropositive for $\mathrm{IgM}$ and $\mathrm{IgG}$, respectively, at the admission; in particular, 11 patients presented both IgM and IgG against SARS-CoV-2 in the serum. The concomitant positivity was maintained up to the day 13 in all the 11 patients; the two patients showing only IgM at $\mathrm{T} 0$ showed a simultaneously $\operatorname{IgM}$ and $\operatorname{IgG}$ positivity at the subsequent follow-up; finally, among the 6 patients who tested $\operatorname{IgG}$ positive at the $\mathrm{T} 0$, four showed a simultaneous $\operatorname{IgM}$ and $\operatorname{IgG}$ positivity after 13 days. The median and geometric mean IgM and IgG level were $1.83 \mathrm{AU} / \mathrm{mL}$ (range: $0.11-14.10$ $\mathrm{AU} / \mathrm{mL}), 1.59 \mathrm{AU} / \mathrm{ml}$ (95\%CI: 0.79-3.22), and 6.70 AU/

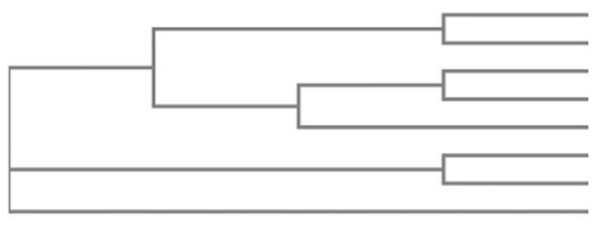

\#15T2 0.10601 \#26T2 0.00121 \#Wuhan-Hu-1 0 \#8T2 0 \#36T3 0.01381 \#32T1 0.01882 \#11T0 0.01667 \#25T1 0.02073

Fig. 2 Phylogenetic relationship of SARS-CoV-2 RBD sequences based on nucleotide sequence from Wuhan-Hu-1 strain confirms that the isolated SARS-CoV-2 sharehigh similarity with the reference strain
$\mathrm{mL}$ (range: 0.06-42.44 AU/mL), $4.70 \mathrm{AU} / \mathrm{ml}$ (95\%CI: 2.03-10.90) at the admission, and significantly increased up to median values of $10.97 \mathrm{AU} / \mathrm{mL}$ (range: $0.75-30.00$ AU/mL, IQR 25.14), 9.88 AU/ml (95\%CI: 5.80-16.83) and 34.01 AU/mL (2.00-45.00 AU/mL), and 24.19 AU/ml (95\%CI: 16.41-35.67) after 13 days, respectively $(p<0.01$ for $\operatorname{IgM}$ and $p=0.01$ for $\operatorname{IgG}$ ). Analytical description of $\operatorname{IgG}$ and IgM levels in the serum collected from each patient, at $\mathrm{T} 0$ and after 13 days, is shown in Fig. 3.

\section{Discussion}

Here, we described the virological and serological assessments of 23 COVID-19 patients admitted at the Istituto Clinico Città Studi, a general hospital, located in Milan, center city, Lombardy, Italy, during the first epidemic wave, providing additional evidence on SARS-CoV-2 shedding.

The focus was made on respiratory, fecal, and blood samples, collected during the patients' hospitalization, until discharge. SARS-CoV-2 genome was found in all the clinical specimens, with similar frequencies in NPS and anal swabs, but much lower frequency in blood samples. As expected, the viral load was significantly higher in the NPS than in the other specimens ( $\mathrm{Li}$ et al. 2020a).

Transmission of SARS-CoV-2 can occur through direct, indirect, or close contact with infected people, through infected secretions such as saliva and respiratory secretions or their respiratory droplets, which are expelled when an infected person coughs, sneezes, talks, or sings (Liu et al. 2020a). However, different possible modes of transmission for SARS-CoV-2, including contact, droplet, airborne, fomite, fecal-oral, bloodborne, mother-to-child, and animal-to-human transmission, have been proposed. Growing 


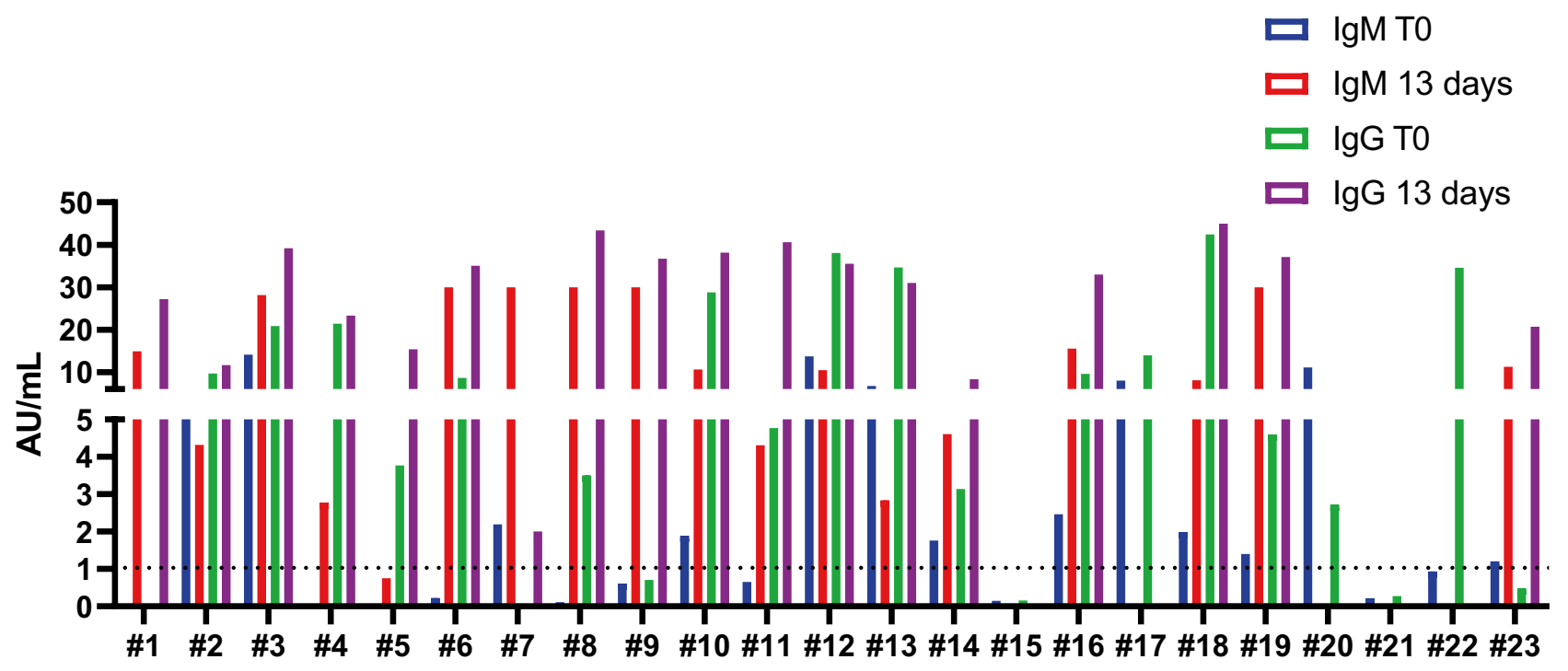

Fig. 3 SARS-CoV-2 IgG and IgM levels for each patient at T0 and after 13 days

evidence has revealed positive detection of viral RNA in anal swabs and fecal samples of patients with COVID-19, at different rates (Novazzi et al. 2020; Wu et al. 2020a; Zhang et al. 2020b). The presence of SARS-CoV-2 RNA in feces samples seemed to peak later (2-5 days), than in NPS swabs, and to persist longer than in respiratory specimens (Jiang et al. 2020; Lin et al. 2021; Lyu et al. 2021; Prakash et al. 2021; Tang et al. 2020; Xing et al. 2020). However, although the frequent presence of SARS-CoV-2 RNA in fecal or rectal swabs, evidence of infectious viruses shedding in feces are limited, and viable virus particles have been rarely reported in feces-related specimens from COVID-19 patients (Xiao et al. 2020), so that some authors are questioning whether the SARS-CoV-2 fecal-oral transmission may be plausible (Pedersen et al. 2021).

In our study, the frequencies of SARS-CoV-2 RNA detection in anal swabs $(86.9 \%)$ and of the gastrointestinal symptoms $(30.4 \%)$ reported in the enrolled patients were greater compared to what observed in other published studies (Zhang et al. 2021). These disparate values may be attributed to the limited number of patients enrolled in our study, or to the sampling time, or the sample type across studies, or the severity of the COVID-19 affecting our patients, and requiring hospitalization of the patients. The persistent positivity was similar in respiratory and feces-related samples, but the median time of negativization was higher in anal than in NPS swabs, and within the average durations, that have been previously reported (Cheung et al. 2020; Wu et al. 2020b). Long-term post-discharge follow-up would be warranted to evaluate the risk of transmission, due to routes different from the respiratory one, and also in the absence of respiratory symptoms, as proposed by Lyu and colleagues (Lyu et al. 2021).
Interestingly, independent studies conducted on young mild symptomatic subjects reported SARS-CoV-2 detection in anal swabs, but not in other clinical specimens from the same patients (Peng et al. 2020; Sun et al. 2020; Zhang et al. 2020a). To this regard, during the same frame of time, four patients admitted at our hospital, but not included in the present study, because with SARS-CoV-2 negative NPSs, showed persistence viral positivity in the anal swabs. About one-third of patients with SARS-CoV-2 positive anal swabs showed gastrointestinal symptoms, such as nausea and diarrhea, and two of them deceased.

Although based on a limited number of patients, our results corroborated the numerous reports of SARS-CoV-2 genome finding in wastewater all over the world (Patel et al. 2021), and the detection of viral genomes in wastewater increasing with the number of COVID-19-related hospitalizations, (Medema et al. 2020), but did not give any information about the infectivity of the shedding viruses, that were not cultured.

However, based on the evident and frequent replication of the virus in the GI tract, the fecal-oral route should be considered as a potential transmission route for SARS-CoV-2, especially in specific environments. Particular attention should be paid in healthcare settings, where COVID-19 patients are forced to share the facilities or to stay in the bed constantly, without the possibility of using the bathroom, but with the continuous use of diapers. The repeated use of shared toilets, together with the infrequent cleaning, might result in progressive accumulation of virus, on the toilet seats, sink, and door handle (Amoah et al. 2021; Chia et al. 2020; Ding et al. 2021; Li et al. 2020b; Ong et al. 2020), where the virus may persist for up to 4 days (Chin et al. 2020). Additionally, the risk of SARS-CoV-2 fecal contamination may be much higher in 
poor-setting countries, characterized by poor sanitation (Jones et al. 2020).

Besides the positivity in the NPS and anal swabs, about $26 \%$ of the patients enrolled in our study, tested positive in the blood samples, with viral loads comparable to that reported in the anal swabs, and persistence of viremia in one patient. A systematic review of the literature identified that the blood from up to $76 \%$ of COVID-19 patients, in critical care settings, may present detectable SARS-CoV-2 RNA. However, in the majority of the cases, SARS-CoV-2 viremia was not detected, and the load was so low that it was outside the threshold, usually reported as positive in diagnostic tests (Andersson et al. 2020, L). Nonetheless, as underlined by Andersson and colleagues, the recognition that SARSCoV-2 RNA may be detected and quantified in blood raised concerns about the safety for personnel handling samples in clinical and research environments (Andersson et al. 2020; Loubaki et al. 2021).

Finally, $\operatorname{IgM}$ and $\operatorname{IgG}$ serum titres were evaluated in the serum samples of each patient at the hospital admission, and after 13 days of hospitalization. Our results showed that the most patients were seropositive for IgM and/or IgG, already at the admission, due to the fact that hospitalization probably occurred some days after the onset of the infections. As expected, the antibody titers significantly increased over the time, reaching the almost complete seroconversion to $\mathrm{IgG}$, about 17-19 days after symptoms onset. This is in line with reports from the literature, concluding that the rate and timing of $\operatorname{IgM}$ and $\mathrm{IgG}$ seroconversion were inconsistent across the independent analyzed studies, but most seroconverted for IgG within 2 weeks and $100 \%$ within 4 weeks (O Murchu et al. 2020; Yadav et al. 2021).

\section{Conclusions}

The main limit of the described study was given by the small cohort size, and by the severe health conditions of the patients, requiring the hospitalization. This implies that the study gave a picture of the SARS-CoV-2 shedding in the most severe cases of COVID-19, and did not reflect the heterogeneity of the mild and asymptomatic infected population.

However, it should be taken into account that the collection of biological samples was carried out from consecutively enrolled patients, at the very beginning of the pandemic. Unfortunately, the hospital in which the patients were recruited was immediately overwhelmed by the unexpected pandemic wave, with unimaginable numbers of hospitalized patients in serious or critical conditions. This event put a strain on the work of doctors and health personnel who could not continue with the systematic collection of biological samples, and who had to limit the collection to nasopharyngeal swabs, obviously essential from a diagnostic point of view.

Although based on limited numbers of subjects and samples, these findings could be helpful for corroborating the model proposed by Sun and colleagues, stating that SARS-CoV-2 infection course could start in the upper respiratory infection (mainly by respiratory droplets), continue in the lower respiratory infection (mainly presented as pulmonary infection), followed by viremia and diffusion to other target organs (including the gastro intestinal tract) (Sun et al. 2020). Furthermore, our results might also be of support for the idea that the spread of SARS-CoV-2 in hospitals and elderly residences, where patients are often constantly bedridden and are not autonomous in the management of their stools, could occur through fecal contamination, involving healthcare personnel in the infection, who usually is able to protect themselves from droplets, wearing masks, but less easily during the direct care and hygiene of patients. Same attentions should be paid when gastrointestinal tract diagnostic or surgical procedures are performed (Deidda et al. 2021), and when stools or vomitus samples are handled. This implies (a) the mandatory use of Personal Protective Equipments (PPE), including disposable coat, mask, gloves, glasses or face shield, and hair cap by healthcare personnel; (b) the promotion and enforcing of hand-hygiene measures, among health personnel and patients; (c) the definition of protocols for the disinfection and decontamination of the surfaces, the room, and the equipments, based on the use of sodium-hypochlorite or similar disinfectants; (d) the definition of strict protocols for the medical procedures, that are considered to be at risk of infection; and (e) when possible, the definition of a washroom design, providing limitation of the contamination risks (i.e., adequate ventilation, non-touch flush buttons, automatic doors) (Vardoulakis et al. 2021).

Supplementary information The online version contains supplementary material available at https://doi.org/10.1007/s13365-021-01029-0.

Acknowledgements All the authors would like to remember their beloved and esteemed colleague, Mrs. Loredana Cavicchini, who devoted all her work time to the research, and lately, to the COVID-19 research. She was one of the young victims of SARS-CoV-2, and this paper is dedicated to her. The authors also would like to thank all the medical and healthcare staff of the Istituto Clinico Città Studi, who have been working with dedication, ability, enthusiasm, and spirit of sacrifice since the beginning of the pandemic.

Author contribution Conceptualization: P.F., E.P., and S.D.; methodology: M.D., L.S, L.C., F.A., and C.G.; investigation: L.S., M.D., R.T., S.P., B.I., and N.B.; resources: P.B., N.C., P.F. and S.D.; data curation: S.B., E.P., A.M., and P.F.; writing-original draft preparation: L.S., and M.D.; writing-review and editing: P.F., S.D., E.P. N.B., F.A. and S.P.; visualization: L.S., and M.D..; supervision: S.D., P.F., N.B.; funding acquisition: S.D., and P.F. All authors have read and agreed to the published version of the manuscript. 
Funding This project was partially supported by MIUR, grant PRIN 2017 to PF, and by the Italian Ministry of Health, grant COVID-2020 12371849 to SD.

Availability of data and materials The datasets supporting the conclusions of this article are included within the article (and its additional file).

\section{Declarations}

Ethics approval and consent to participate Clinical specimens were collected upon approval of the Local Ethical Committee and signature of the informed consent (Fondazione Ca' Granda, Ospedale Maggiore, Milano, Italy, approved the protocol 456_2020, on May 2020).

Conflict of interest The authors declare no competing interests.

\section{References}

Ahmad J, Ahmad M, Usman ARA, Al-Wabel MI (2021) Prevalence of human pathogenic viruses in wastewater: a potential transmission risk as well as an effective tool for early outbreak detection for COVID-19. J Environ Manage 298:113486

Ahmed Moustafa RKA (2020) Traces of SARS-CoV-2 RNA in the blood of COVID-19 patients. medRxiv

Alanagreh L, Alzoughool F, Atoum M (2020) The human coronavirus disease COVID-19: its origin, characteristics, and insights into potential drugs and its mechanisms. Pathogens 29;9(5):331

Amoah ID, Pillay L, Deepnarian N, Awolusi O, Pillay K, Ramlal P, Kumari S, Bux F (2021) Detection of SARS-CoV-2 RNA on contact surfaces within shared sanitation facilities. Int J Hyg Environ Health 236:113807

Andersson MI, Arancibia-Carcamo CV, Auckland K, Baillie JK, Barnes E, Beneke T, Bibi S, Brooks T, Carroll M, Crook D, Dingle K, Dold C, Downs LO, Dunn L, Eyre DW, Gilbert Jaramillo J, Harvala H, Hoosdally S, Ijaz S, James T, James W, Jeffery K, Justice A, Klenerman P, Knight JC, Knight M, Liu X, Lumley SF, Matthews PC, McNaughton AL, Mentzer AJ, Mongkolsapaya J, Oakley S, Oliveira MS, Peto T, Ploeg RJ, Ratcliff J, Robbins MJ, Roberts DJ, Rudkin J, Russell RA, Screaton G, Semple MG, Skelly D, Simmonds P, Stoesser N, Turtle L, Wareing S, Zambon M (2020) SARS-CoV-2 RNA detected in blood products from patients with COVID-19 is not associated with infectious virus. Wellcome Open Res 5:181

BLAST: Basic local alignment search tool. https://blast.ncbi.nlm.nih. gov/Blast.cgi. Accessed in September 2020

Centers for Disease Control and Prevention. https://www.cdc.gov/ coronavirus/2019-ncov/lab/rt-pcr-panel-primer-probes.html. Accessed in March 2020

Cheung KS, Hung IFN, Chan PPY, Lung KC, Tso E, Liu R, Ng YY, Chu MY, Chung TWH, Tam AR, Yip CCY, Leung KH, Fung AY, Zhang RR, Lin Y, Cheng HM, Zhang AJX, To KKW, Chan KH, Yuen KY, Leung WK (2020) Gastrointestinal manifestations of SARS-CoV-2 infection and virus load in fecal samples from a Hong Kong cohort: systematic review and Meta-analysis. Gastroenterology 159:81-95

Chia PY, Coleman KK, Tan YK, Ong SWX, Gum M, Lau SK, Lim XF, Lim AS, Sutjipto S, Lee PH, Son TT, Young BE, Milton DK, Gray GC, Schuster S, Barkham T, De PP, Vasoo S, Chan M, Ang BSP, Tan BH, Leo YS, Ng OT, Wong MSY, Marimuthu K, Team SNCOR (2020) Detection of air and surface contamination by
SARS-CoV-2 in hospital rooms of infected patients. Nat Commun 11:2800

Chin AWH, Chu JTS, Perera MRA, Hui KPY, Yen HL, Chan MCW, Peiris M, Poon LLM (2020) Stability of SARS-CoV-2 in different environmental conditions. Lancet Microbe 1:e10

Ciccarelli FD, Doerks T, von Mering C, Creevey CJ, Snel B, Bork P (2006) Toward automatic reconstruction of a highly resolved tree of life. Science 311:1283-1287

Deidda S, Tora L, Firinu D, Del Giacco S, Campagna M, Meloni F, Orrù G, Chessa L, Carta MG, Melis A, Spolverato G, Littera R, Perra A, Onali S, Zorcolo L, Restivo A (2021) Gastrointestinal coronavirus disease 2019: epidemiology, clinical features, pathogenesis, prevention, and management. Expert Rev Gastroenterol Hepatol 15:41-50

Ding Z, Qian H, Xu B, Huang Y, Miao T, Yen HL, Xiao S, Cui L, Wu X, Shao W, Song Y, Sha L, Zhou L, Xu Y, Zhu B, Li Y (2021) Toilets dominate environmental detection of severe acute respiratory syndrome coronavirus 2 in a hospital. Sci Total Environ 753:141710

Hikmet F, Méar L, Edvinsson Å, Micke P, Uhlén M, Lindskog C (2020) The protein expression profile of ACE2 in human tissues. Mol Syst Biol 16:e9610

Jiang X, Luo M, Zou Z, Wang X, Chen C, Qiu J (2020) Asymptomatic SARS-CoV-2 infected case with viral detection positive in stool but negative in nasopharyngeal samples lasts for 42 days. J Med Virol 92:1807-1809

Jin B, Singh R, Ha SE, Zogg H, Park PJ, Ro S (2021) Pathophysiological mechanisms underlying gastrointestinal symptoms in patients with COVID-19. World J Gastroenterol 27:2341-2352

Jones DL, Baluja MQ, Graham DW, Corbishley A, McDonald JE, Malham SK, Hillary LS, Connor TR, Gaze WH, Moura IB, Wilcox MH, Farkas K (2020) Shedding of SARS-CoV-2 in feces and urine and its potential role in person-to-person transmission and the environment-based spread of COVID-19. Sci Total Environ 749:141364

Koyama T, Platt D, Parida L (2020) Variant analysis of SARS-CoV-2 genomes. Bull World Health Organ 98:495-504

Li H, Ren L, Zhang L, Wang Y, Guo L, Wang C, Xiao Y, Rao J, Wang X, Liu Y, Huang C, Gu X, Fan G, Lu B, Cao B, Wang J (2020a) High anal swab viral load predisposes adverse clinical outcomes in severe COVID-19 patients. Emerg Microbes Infect 9:2707-2714

Li YH, Fan YZ, Jiang L, Wang HB (2020b) Aerosol and environmental surface monitoring for SARS-CoV-2 RNA in a designated hospital for severe COVID-19 patients. Epidemiol Infect 148:e154

Lin W, Xie Z, Li Y, Li L, Wen C, Cao Y, Chen X, Ou X, Hu F, Li F, Tang X, Cai W (2021) Association between detectable SARSCOV-2 RNA in anal swabs and disease severity in patients with coronavirus disease 2019. J Med Virol 93:794-802

Liu J, Liao X, Qian S, Yuan J, Wang F, Liu Y, Wang Z, Wang FS, Liu L, Zhang Z (2020a) Community transmission of severe acute respiratory syndrome coronavirus 2, Shenzhen, China, 2020. Emerg Infect Dis 26:1320-1323

Liu W, Liu L, Kou G, Zheng Y, Ding Y, Ni W, Wang Q, Tan L, Wu W, Tang S, Xiong Z, Zheng S (2020b) Evaluation of nucleocapsid and spike protein-based enzyme-linked immunosorbent assays for detecting antibodies against SARS-CoV-2. J Clin Microbiol 58(6):e00461-e520

Loubaki L, Gantner P, Pagliuzza A, Fausther-Bovendo H, Kobinger G, Chomont N, Germain M (2021) Testing for the presence of SARS-CoV-2 RNA in presymptomatic blood donors. Transfusion 61(2):649-651

Lyu Y, Wang D, Li X, Gong T, Xu P, Liu L, Sun J (2021) Continued nucleic acid tests for SARS-CoV-2 following discharge of patients with COVID-19 in Lu'an. China. Peerj 9:e11617 
Masiá M, Telenti G, Fernández M, García JA, Agulló V, Padilla S, García-Abellán J, Guillén L, Mascarell P, Asenjo JC, Gutiérrez F (2021) SARS-CoV-2 seroconversion and viral clearance in patients hospitalized with COVID-19: viral load predicts antibody response. Open Forum Infect Dis 8(2):ofab005

Medema GHL, Elsinga G, Italiaander R, Brouwer A (2020) Presence of SARS-Coronavirus-2 RNA in sewage and correlation with reported COVID-19 prevalence in the early stage of the epidemic in The Netherlands. Environ Sci Technol Lett 7(7):511-516

Meselson M (2020) Droplets and aerosols in the transmission of SARSCoV-2. N Engl J Med 382:2063

Novazzi F, Cassaniti I, Piralla A, Di Sabatino A, Bruno R, Baldanti F (2020) SARS-CoV-2 positivity in rectal swabs: implication for possible transmission. J Glob Antimicrob Resist 22:754-755

O Murchu E, Byrne P, Walsh KA, Carty PG, Connolly M, De Gascun C, Jordan K, Keoghan M, O'Brien KK, O’Neill M, Smith SM, Teljeur C, Ryan M, Harrington P (2020) Immune response following infection with SARS-CoV-2 and other coronaviruses: A rapid review. Rev Med Virol 31(2):e2162

Ong SWX, Tan YK, Chia PY, Lee TH, Ng OT, Wong MSY, Marimuthu K (2020) Air, surface environmental, and personal protective equipment contamination by severe acute respiratory syndrome coronavirus 2 (SARS-CoV-2) from a symptomatic patient. JAMA 323:1610-1612

Patel M, Chaubey AK, Pittman CU, Mlsna T, Mohan D (2021) Coronavirus (SARS-CoV-2) in the environment: Occurrence, persistence, analysis in aquatic systems and possible management. Sci Total Environ 765:142698

Pedersen RM, Tornby DS, Bang LL, Madsen LW, Skov MN, Jensen TG, Johansen IS, Andersen TE (2021) Rectally shed SARS-CoV-2 lacks infectivity: time to rethink faecal-oral transmission? Nat Rev Gastroenterol Hepatol 18:669

Peng L, Liu J, Xu W, Luo Q, Chen D, Lei Z, Huang Z, Li X, Deng $\mathrm{K}$, Lin B, Gao Z (2020) SARS-CoV-2 can be detected in urine, blood, anal swabs, and oropharyngeal swabs specimens. J Med Virol 92:1676-1680

Prakash S, Shukla S, Mishra H, Prakash O, Khan DN, Pandey A, Reddy DH, Jain A (2021) SARS-CoV-2 -RNA persists longer in faecal sample as compared to nasal and throat swab samples of COVID-19 patients'; an observational study. Indian J Med Microbiol 39:122-124

Sievers F, Wilm A, Dineen D, Gibson TJ, Karplus K, Li W, Lopez R, McWilliam H, Remmert M, Söding J, Thompson JD, Higgins DG (2011) Fast, scalable generation of high-quality protein multiple sequence alignments using Clustal Omega. Mol Syst Biol 7:539

Sun M, Guo D, Zhang J, Teng HF, Xia J, Liu P, Ge QX, Wang MY (2020) Anal swab as a potentially optimal specimen for SARSCoV-2 detection to evaluate hospital discharge of COVID-19 patients. Future Microbiol 15:1101-1107

Tang A, Tong ZD, Wang HL, Dai YX, Li KF, Liu JN, Wu WJ, Yuan C, Yu ML, Li P, Yan JB (2020) Detection of novel coronavirus by RT-PCR in stool specimen from asymptomatic child, China. Emerg Infect Dis 26:1337-1339
Vardoulakis S, Espinoza Oyarce DA, Donner E (2021) Transmission of COVID-19 and other infectious diseases in public washrooms: a systematic review. Sci Total Environ 803:149932

Villani L, McKee M, Cascini F, Ricciardi W, Boccia S (2020) Comparison of deaths rates for COVID-19 across Europe during the first wave of the COVID-19 pandemic. Front Public Health 8:620416

Wang W, Xu Y, Gao R, Lu R, Han K, Wu G, Tan W (2020) Detection of SARS-CoV-2 in different types of clinical specimens. JAMA 323:1843-1844

Wu J, Liu J, Li S, Peng Z, Xiao Z, Wang X, Yan R, Luo J (2020a) Detection and analysis of nucleic acid in various biological samples of COVID-19 patients. Travel Med Infect Dis 37:101673

Wu Y, Guo C, Tang L, Hong Z, Zhou J, Dong X, Yin H, Xiao Q, Tang Y, Qu X, Kuang L, Fang X, Mishra N, Lu J, Shan H, Jiang G, Huang X (2020b) Prolonged presence of SARS-CoV-2 viral RNA in faecal samples. Lancet Gastroenterol Hepatol 5:434-435

Xiao F, Tang M, Zheng X, Liu Y, Li X, Shan H (2020) Evidence for gastrointestinal infection of SARS-CoV-2. Gastroenterology 158:1831-1833.e3

Xing YH, Ni W, Wu Q, Li WJ, Li GJ, Wang WD, Tong JN, Song XF, Wing-Kin Wong G, Xing QS (2020) Prolonged viral shedding in feces of pediatric patients with coronavirus disease 2019. J Microbiol Immunol Infect 53:473-480

Yadav AK, Ghosh S, Kotwal A, Kaushik SK, Bobdey S, Sahu R, Kapoor S, Faujdar DS, Teli PT, Anand V (2021) Seroconversion among COVID-19 patients admitted in a dedicated COVID hospital: a longitudinal prospective study of 1000 patients. Med J Armed Forces India 77(Suppl 2):S379-S384

Zhang B, Liu S, Dong Y, Zhang L, Zhong Q, Zou Y, Zhang S (2020a) Positive rectal swabs in young patients recovered from coronavirus disease 2019 (COVID-19). J Infect 81:e49-e52

Zhang W, Du RH, Li B, Zheng XS, Yang XL, Hu B, Wang YY, Xiao GF, Yan B, Shi ZL, Zhou P (2020b) Molecular and serological investigation of 2019-nCoV infected patients: implication of multiple shedding routes. Emerg Microbes Infect 9:386-389

Zhang Y, Cen M, Hu M, Du L, Hu W, Kim JJ, Dai N (2021) Prevalence and persistent shedding of fecal SARS-CoV-2 RNA in patients with COVID-19 infection: a systematic review and meta-analysis. Clin Transl Gastroenterol 12:e00343

Zhao J, Yuan Q, Wang H, Liu W, Liao X, Su Y, Wang X, Yuan J, Li T, Li J, Qian S, Hong C, Wang F, Liu Y, Wang Z, He Q, Li Z, He B, Zhang T, Fu Y, Ge S, Liu L, Zhang J, Xia N, Zhang Z (2020) Antibody responses to SARS-CoV-2 in patients with novel coronavirus disease 2019. Clin Infect Dis 71:2027-2034

Zhu N, Zhang D, Wang W, Li X, Yang B, Song J, Zhao X, Huang B, Shi W, Lu R, Niu P, Zhan F, Ma X, Wang D, Xu W, Wu G, Gao GF, Tan W (2020) A novel coronavirus from patients with pneumonia in China, 2019. N Engl J Med 382:727-733

Publisher's Note Springer Nature remains neutral with regard to jurisdictional claims in published maps and institutional affiliations. 


\section{Authors and Affiliations}

\section{Lucia Signorini ${ }^{1}$ - Maria Dolci ${ }^{1}$. Nicolò Castelnuovo ${ }^{2} \cdot$ Luigia Crespi $^{2} \cdot$ Barbara Incorvaia $^{2} \cdot$ Pietro Bagnoli $^{2}$. Silvia Parapini ${ }^{3} \cdot$ Nicoletta Basilico $^{1} \cdot$ Cristina Galli $^{3} \cdot$ Federico Ambrogi $^{4,5}$ - Elena Pariani ${ }^{3}$. Sandro Binda ${ }^{3}$. Rosalia Ticozzi $^{1} \cdot$ Pasquale Ferrante $^{1,2}(\mathbb{0}) \cdot$ Serena Delbue ${ }^{1}$}

Lucia Signorini

lucia.signorini@unimi.it

Maria Dolci

maria.dolci@unimi.it

Nicolò Castelnuovo

nicolo.castelnuovo@ic-cittastudi.it

Luigia Crespi

luigia.crespi@ic-cittastudi.it

Barbara Incorvaia

barbara.incorvaia@ic-cittastudi.it

Pietro Bagnoli

pietro.bagnoli@ic-cittastudi.it

Silvia Parapini

silvia.parapini@unimi.it

Nicoletta Basilico

Nicoletta.basilico@unimi.it

Cristina Galli

cristina.galli@unimi.it

Federico Ambrogi

Federico.ambrogi@unimi.it
Elena Pariani

elena.pariani@unimi.it

Sandro Binda

Sandro.binda@unimi.it

Rosalia Ticozzi

rosalia.ticozzi@unimi.it

Serena Delbue

serena.delbue@unimi.it

1 Department of Biomedical, Surgical and Dental Sciences, University of Milan, Via Pascal 36, 20133 Milan, Italy

2 Istituto Clinico Città Studi (ICCS), Via Jommelli 17, 20133 Milan, Italy

3 Department of Biomedical Sciences for Health, University of Milan, Milan, Italy

4 Department of Clinical and Community Sciences, University of Milan, Milan, Italy

5 Scientific Directorate, IRCCS Policlinico San Donato, San Donato Milanese, Milan, Italy 